nates. To pass the smallest Eustachian catheter was out of the question. I succeeded in getting the effect of a 25 per cent. solution in the anterior and posterior nares, with the result of opening the canal in one treatment sufficiently to afford nasal respiration and sufficient space for catheterization. Another treatment increased the freedom of respiration, and subsequent treatments maintained the patulous condition of the nostrils, thus obviating the necessity of any operation with the knife, saw or cautery.

While writing these observations, an old college classmate, Mr. H., of Hutchinson, entered my office, suffering from an attack of acute laryngitis. He was unable to speak aloud. I gave him two inhalations during the forenoon, first with a 5 per cent. solution, and later with the ro per cent. The following morning his voice had returned with nearly the customary strength and smoothness. After one inhalation more, his voice became normal, and all symptoms of laryngitis vanished.

One of my assistants, Dr. Collins, restored his voice from an enforced whisper to a good speaking condition in twenty-four hours by treating an attack of laryngitis with the inhalations, varying in strength from ro to 20 per cent.

In hypertrophic nasal catarrh, with excessive discharge, a 25 per cent. solution, $i . e ., 121 / 2$ per cent. each of the camphor and menthol, and 75 per cent. of lavoline, has checked the discharge, given it a healthy character, and restored nasal respiration.

I have had four assistants conducting experiments parallel with mine. The experiences of two have been briefly referred to. One of the others, Dr. Davey, reports having obtained results corresponding to mine, and the fourth, Dr. Campbell, compares the action of camphor-menthol with that of cocaine, excepting the powerful anæsthetic effect of the latter.

The important point to be emphasized in the use of this, as well as other potent remedies, is the choice of the proper strength in adapting it to each individual case in order to secure the best results. In chronic hypertrophic rhinitis in a person of dull sensibilities, a 25 per cent. solution may be used with excellent effect; whereas, in the opposite extreme of temperament, in which the Schneiderian membrane is exquisitely hypersensitive, a first inhalation stronger than the 3 , or 5 , per cent. solution, may appear to act as an irritant.

I have injected a ro per cent. preparation in lavoline into the Eustachian tube, which was closed so firmly that it was impossible to inflate the middle ear by the Valsalva or Politzer method, with the result of opening the tube so well that on the following day there was no difficulty in injecting remedies through it into the tympanic carity. This has occurred repeatedly.
No ill results have followed the injection of 5 and 10 per cent. solutions into the middle ear, but in several cases of catarrhal affections of that cavity the hearing was improved and the head has felt clearer after the injections.

I have applied the full strength camphormentiol to eczematous eruptions and found that it relieved the pruritus and reduced the swelling and redness. It had a similar effect in herpetic eruptions.

Finally, camphor-menthol contracts the capillary blood-vessels of the mucous membrane, reduces swelling, relieves pain and fullness of the head, or stenosis, arrests sneezing, checks excessive discharges and corrects perverted secretions.

70 State street, Chicago.

\section{SHOULD PHYSICAL RESTRAINT BE USED IN THE TREATMENT OF THE INSANE.}

BY ARTHUR LOEWY, M.D.,

assistant physician coOk colnty hosprtal for the insane.

A question important both to the physicians in charge of the insane, and to the general public, is, "Shall physical restraint be used in the treatment of the insane?" This question has agitated the minds of officials in whose charge the insane have been placed, and has been for them a difficult problem to solve. I think that I may justly claim that those who have been intimately connected with this work will say that physical restraint, when properly and judiciously used, is a very important factor in the intelligent care and treatment of the insane. Physical restraint may be used for the following objects: First. To prevent the patient from injuring himself or herself. Second. To prevent the patient from injuring others, Third. When, for some bodily injury or ailment, it becomes necessary to apply restraint to secure proper action of some therapeutic reagent. Fourth. When patients remove their clothing. In those cases of insanity where there is a disposition on the part of the patient to injure him or herself, by thrusting the hand through window panes, by attempts of selfinjury by throwing himself or herself on the floor, or by striking the head against the wall, or if the patient be suicidal, and make the most desperate attempts at self-destruction, the question arises, How shall we restrain this patient so that he may not injure himself, nor succeed in accomplishing that which is so dreaded in all hospitals for the insane, namely: suicide? The general public, as a rule, holds up its hands in horror when some sensational report is circulated by the press, that patients in a given asylum have been seen who had their hands in restraint, some strapped to the bench-or even greater, 
when it is said that a patient has been seen in a strait jacket. In all such cases as I have cited above, our first object must be to restrain the patient by carefully watching his every move, and prevent the carrying out of those designs of selfinjury or self-destruction. But in doing this we must have a requisite number of attendants, so that no bodily injury be done in caring for him. In most of our public institutions we find so

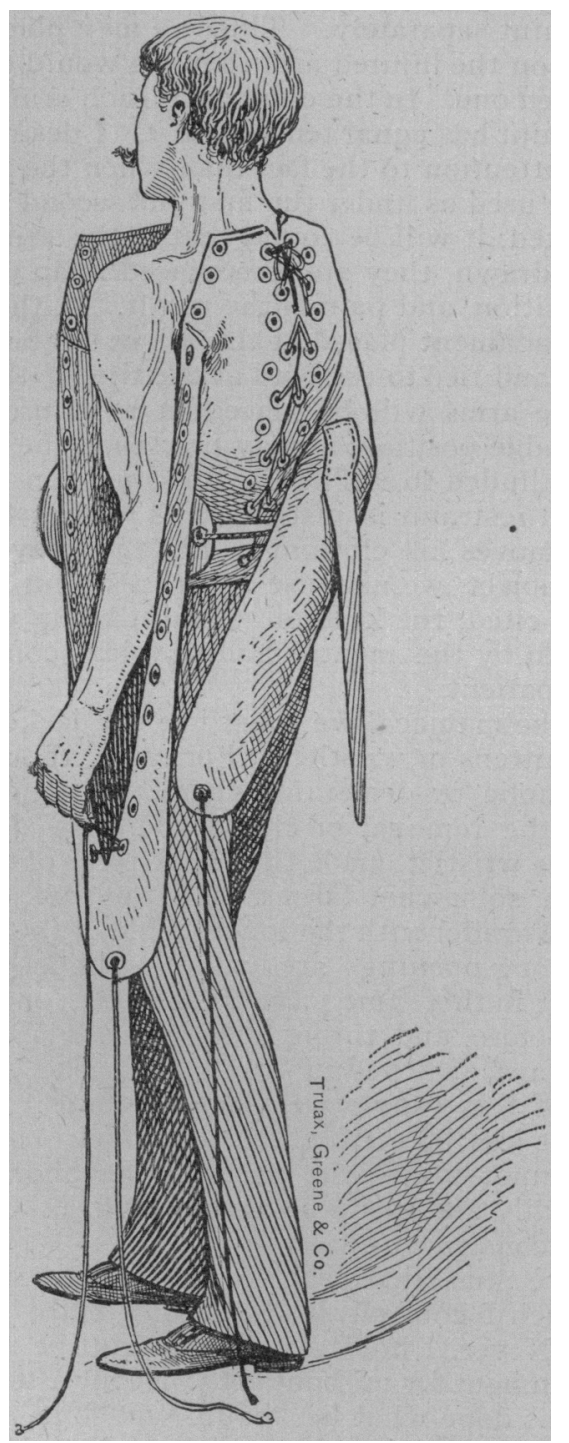

many patients of the class I have just depicted, that it is an utter impossibility to assign to this special duty a sufficient corps of attendants. It is under these circumstances that physical restraint is justifiable. If a patient attack other patients in the ward, he must be so restrained that he can do no injury to others; at the same time it must be taken into consideration that restraint in this case cannot be called beneficial to that patient's mental condition. It is simply a means of protection to those patients who are in the same ward, and to those in whose charge this particular patient may be. In the treatment of any number of the insane, the care of each case has a bearing on every case in the same ward, Hence, to prevent injury to other patients, and oftentimes even to preserve their lives, restraint must be applied. For either of these conditions, namely: a patient attempting self-injury or injury

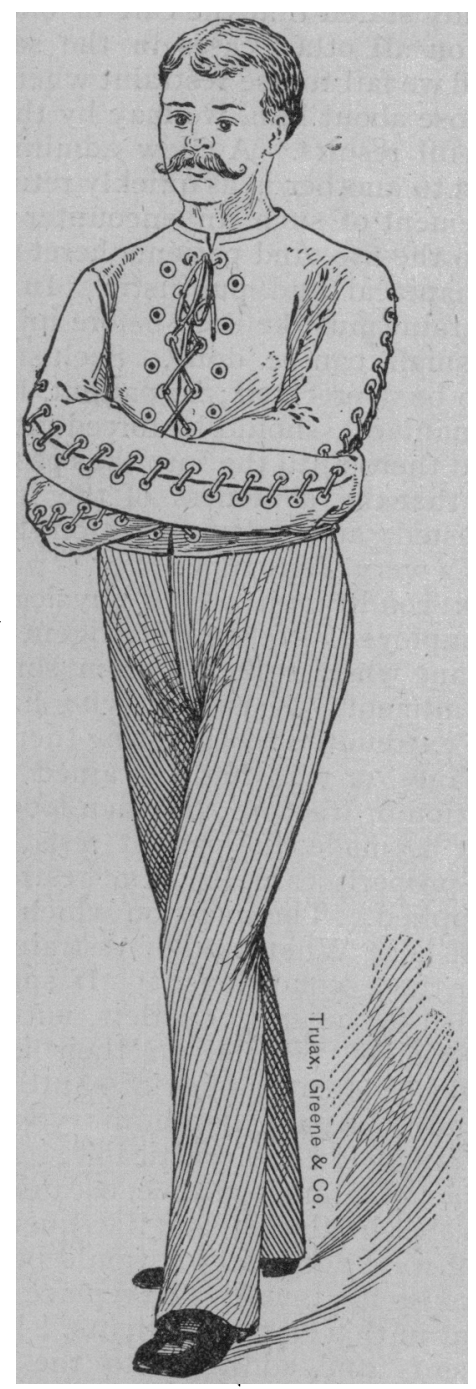

to those about him, the following means of restraint suggest themselves : First. The patient is seated on a bench, a strap is fastened around the patient's waist and through the arm of the bench. Second. The wristlets. Third. Mittens and muff. Fourth. Strait jacket. Should a patient in a paroxysm of furor attack those about him, and other means having failed, physical restraint becomes necessary, I would give preference to the 
first means. I have repeatedly seen, in my association in the care of the insane, patients rapidly become quiet and composed when fastened to the bench. Should, however, this fail to accomplish the end desired, namely: to prevent the patient from injuring him or herself or other patients, some other means must be employed. In such an event I should prefer wristlets, and following this the muff and mittens. For female patients, should the first means fail, the strait jacket, properly applied, is much more to be preferred. I have already stated that the care of one case has a bearing on all other cases in the same ward, and should we fail to use restraint when a patient attacks those about him, we may by this neglect cause direful results. A blow administered by one patient to another is as quickly returned, and the excitement of such an encounter will only add fuel to the fire, and patients heretofore quiet become maniacal and pugilistic. In all such cases, restraint must be used before injury, be it great or small, can be done. Seclusion of patients is to be deprecated; no patient, because he becomes maniacal, should be forced into a room and locked there until the furor has passed away. It is here that the acuteness of the insane may be manifested, and self-destruction be accomplished in a very short time.

The next condition in which physical restraint must be employed, is for the intelligent treatment of the insane when suffering from some bodily injury or ailment. A patient who has injured the upper extremities by thrusting them through window panes, or who has sustained an injury, as dislocation or fracture; or when local applications must be made, the patient resisting all attempts to properly care for him, restraint must then be applied. The question which then presents itself is, "What kind of restraint shall we use under these conditions?" If splints have been applied to the arm, wristlets, mittens or the muff are useless, because in their application there would be great danger of shutting off the blood supply. Again, if the injury were one of the hand, it would be impracticable. Again, the old strait jacket is impracticable, because we conld not watch the circulation, and if frequent changes of dressing were necessary, it would be a hinderance to proper treatment. To replace all modes of restraint in this class of patients, I have made improvements and additions to the old strait jacket, a cut of which is herewith shown.

The Benson Strait Jacket, as this is known, consists in having an opening in the front corresponding to the one in the back, and further, an opening in the sleeve from the neck to the tips of the fingers. By means of this jacket, a patient being confined to bed with some ailment requiring constant use of poultices, the poultices can be changed without raising the patient to the sitting posture, as must be done when the old pointed. jacket is used, thereby avoiding the dangers of death from heart failure. The opening in the sleeve permits the physician to have knowledge at all times as to the condition of the injured member, and should swelling ensue after the application of a splint or cast, immediate knowledge can be had of the fact. An attachment is. placed at the elbow, which is brought around the back and fastened to the cord at the tip of the fingers, thereby permitting each arm to be put in restraint separately. Thus we may place less tension on the injured arm than we would on the uninjured one. In the old jacket, each arm when in restraint has equal tension on it. I desire here to call attention to the fact that, when the jacket must be used as under the first and second conditions cited, it will be found that if the arms are tightly drawn, they are thus placed in an unnatural position, and pain is the result. If, though, this attachment placed at the elbow be brought. around and tied to the cord at the tips of the fingers, the arms will be placed in a natural and comfortable position, as may be seen in the figure before alluded to. The fourth condition where physical restraint is justifiable, is where the patient removes his clothing. For the prevention of this object, we may use all the restraint I have already cited, the kind of restraint being wholly governed by the mental and physical condition of the patient.

For the maniacal we must use the jacket, the muff, mittens or wristlets. For cases, though, of melancholia or dementia, where the patient attempts the removal of clothing, I have devised a canvas wristlet, made thus: A piece of canvas is taken, somewhat larger than the size of the wrist. Parallel with the longest side of the cloth, two oblong openings are made. The loops are then cut in this same piece to fit in the openings made before, and through these loops a belt is drawn, and fastened in the back. The advantages of this canvas wristlet are these: First. There is less idea of restraint in their use, and they cannot injure the patient. Second. They can readily and easily be made. Third. Cheapness in construction.

I have thus laid down the four conditions under which I hold physical restraint to be justifi. able. Never, I hold, should restraint be used as a punishment for misconduct. Never after a patient has done what he should not, but to prerent him from doing that which tends to his own disadvantage, and which prevents or postpones the recovery of his mental health, or for the safety of others, should restraint be applied.

PROF. JOHN J. REESE has resigned the chair he has so long filled in the University of Pennsylvania. His successor has not yet been ap- 